\title{
Liberals promise family doctors for all but is it realistic?
}

Cite as: CMAJ 2019 November 4;191:E1231-2. doi: 10.1503/cmaj.1095827

Posted on cmajnews.com on Oct. 17, 2019

A major plank of the Liberal Party's federal election platform was a promise to ensure that everyone in Canada has access to a family doctor or primary health care team. The party pledged $\$ 6$ billion over four years to support the commitment. Around five million Canadians lack access to primary care.

"No one should go without the care they need because they don't have access to a family doctor," Prime Minister Justin Trudeau said in a press release. "We're going to close the gaps in the health care system, and make sure people can get the care they need, when they need it most."

But the Liberals' promise is light on details other than their pledge to work with provinces and territories. Doctors and patient advocates wonder whether the commitment is realistic and achievable.

"I welcome the fact that various parties are talking about this, but if there are no specifics, it remains a promise, not something that can be implemented," says Dr. Mary Fernando, a retired family physician in Ottawa.

Efforts to provide family doctors for everyone are complicated by a variety of factors. The population is aging, and increasingly people require more frequent and complex care. Many doctors retire from practice each year, often without succession plans in place. And younger doctors are looking for more flexible ways to practise medicine.

Perhaps the most useful contribution the federal government could make in this area would be to gather more and better data about the health care workforce in Canada, says Ivy Bourgeault, a health workforce researcher at the University of Ottawa who leads the Canadian
Health Workforce Network. "If you are going to go out making a promise that everyone's going to have access, you should have a really good handle on who is available to provide that care in the first place," she says. "And that is where the federal government can play a role, but is, in my opinion, not doing a very good job."

Though the health workforce accounts for $70 \%$ of the cost of the health system, only a tiny fraction of the Canadian Institutes of Health Research's (CIHR) budget provinces and municipalities improve how primary care provision is planned and distributed, which would be more productive than merely focusing on increasing head counts, she says.

"We have more physicians now than we've ever had before, but we're not measuring or planning in a way that reflects reality of how they're practising differently," she says. "If you're not measuring properly, how do you know if you've improved the situation?"

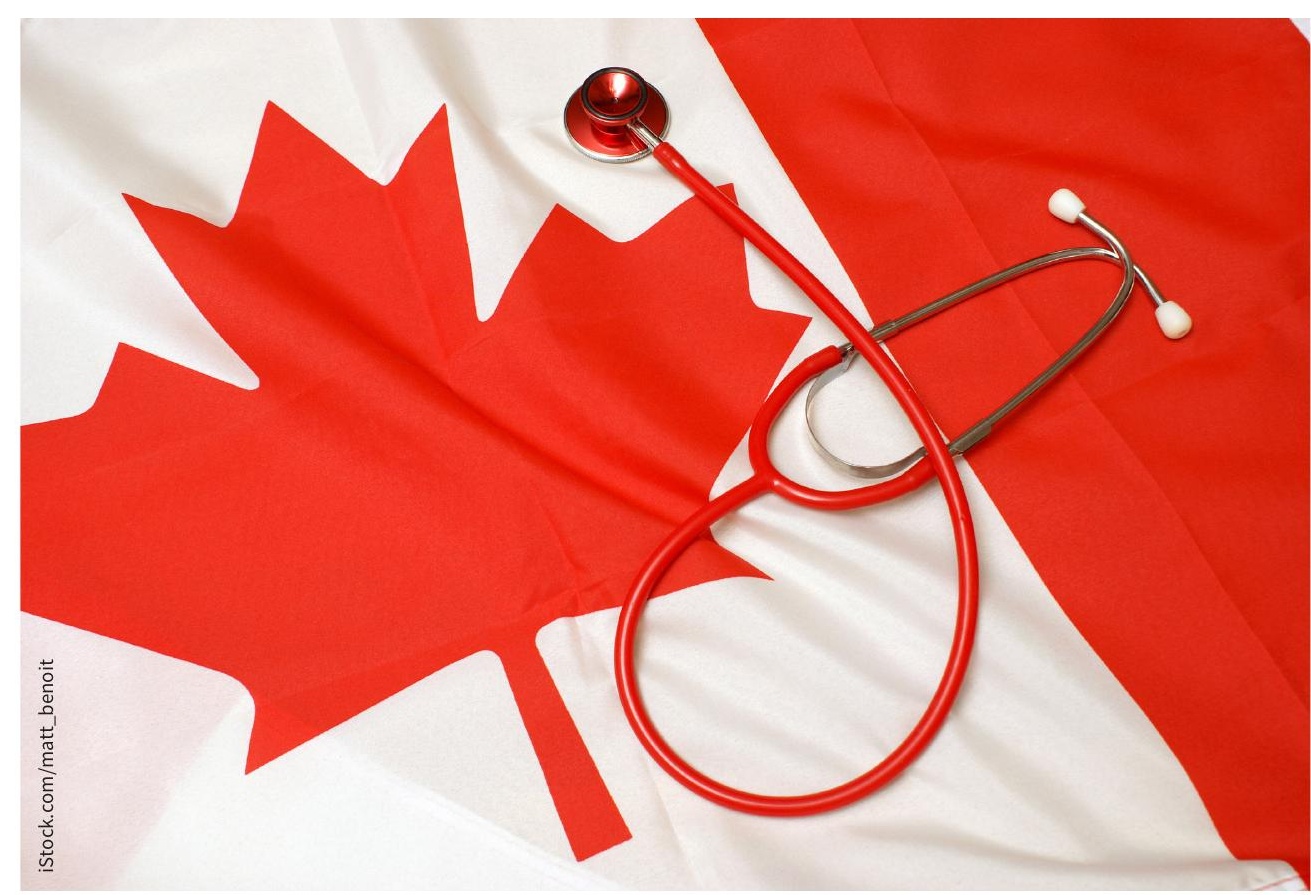

Providing a family physician for every Canadian would be a difficult feat to accomplish, say health workforce experts.

goes to research on health workforce issues, says Bourgeault, so good information on patient needs and physician availability is lacking. Boosting health workforce research at CIHR would help
There have been attempts at the provincial level, with limited success, to ensure everyone has access to primary care, whether in the form of a traditional family doctor, a nurse practitioner or a 
primary care team. In 2013, British Columbia launched A GP for Me, which involved 150 projects to increase practitioners' capacity to take on new patients, support vulnerable patients better and strengthen doctor-patient relationships. The program ended in 2016 and provided doctors for 178000 people who hadn't had one previously. But it didn't find a doctor for everyone.

Fernando says a crucial missing piece in the discussion of primary care provision is the similar shortfall of specialist care. A lack of specialists and long wait times for referrals mean many family doctors are forced to manage patients outside their skill sets. This prevents them from taking on new patients, because they have to spend more time on complex conditions. "We can't omit the specialist piece," she says.

One way to improve the numbers of both primary care practitioners and specialists would be to focus on retaining doctors, says Fernando. The federal government could improve in this area by changing federal tax law to allow provinces and territories to contribute to physician pensions. "Pensions are the best low-cost tool for retention," she says. "It would give provinces another tool in their belt."

Brian Owens, St. Stephen, NB 